\title{
Matrix Precipitation for the Analysis of High-Purity Tin Metal by Electrothermal Atomic Absorption Spectrometry
}

\author{
Masataka Hiraide, Zuo-Sheng Chen, Hajime NakamaChi and Hiroshi Kawaguchi \\ Department of Materials Science and Engineering, Nagoya University, \\ Nagoya 464-01, Japan
}

Keywords Matrix precipitation, tin(IV) hydroxide, stannic acid, trace metals, electrothermal atomic absorption spectrometry

The determination of trace impurities in high-purity materials is essential for the control of their quality as well as for a better understanding of the synergistic action and correlation of the impurities. Separation procedures are generally required, before the determination, for improving the accuracy and precision of analytical results..$^{1-3}$

The Japanese Industrial Standards Committee recommends that we determine trace impurities in tin metal. ${ }^{4}$ Gram quantities of tin are dissolved in aqua regia and volatilized as bromide; the residue is then analyzed for copper and lead by flame-AAS or inductively coupled plasma-atomic emission spectrometry. The procedure, however, is laborious and timeconsuming. The detection limits are not enough to determine the impurities at fractional $\mu \mathrm{g} \mathrm{g}^{-1}$ levels. Direct atomization of a tin sample in a graphite-cup cuvette needs the polarized Zeeman background correction. 5 The method is simple and rapid, but the precision and detectability are insufficient. The analysis based on vaporization kinetics in electrothermal atomic absorption spectrometry (ETAAS) includes a complicated procedure and the accuracy of analytical data is poor. ${ }^{6}$

The present paper describes a simple matrix precipitation technique. The tin matrix is first precipitated as hydroxide along with trace impurities and then removed from the impurities as stannic acid. ${ }^{7}$ The proposed separation method has been successfully combined with ETAAS and applied to the analysis of commercial highpurity tin metal.

\section{Experimental}

\section{Apparatus}

A Seiko I\&E SAS-760 atomic absorption spectrometer was used in conjunction with an SAS-715 graphitefurnace atomizer and a deuterium background corrector. Profiles of the analytical signal and background ab- sorption were indicated on a cathode-ray tube incorporated in the instrument. The pyrolytic graphite tube was first heated during $10 \mathrm{~s}$ to $150^{\circ} \mathrm{C}$, held for $20 \mathrm{~s}$ and then heated during $10 \mathrm{~s}$ to $700^{\circ} \mathrm{C}$ (except for $\mathrm{Cd}, 500^{\circ} \mathrm{C}$ ) and held for $20 \mathrm{~s}$. The graphite tube was further heated to atomization temperatures: $2200^{\circ} \mathrm{C}$ (for $\mathrm{Cd}$ and $\mathrm{Pb}$ ), $2300^{\circ} \mathrm{C}$ (for $\mathrm{Cu}$ ) and $2400^{\circ} \mathrm{C}$ (for $\mathrm{Fe}$ ). The wavelengths (in $\mathrm{nm}$ ) used were $\mathrm{Cu} 324.8, \mathrm{Cd} 228.8, \mathrm{~Pb} 217.0$ and $\mathrm{Fe}$ 248.3. Hollow-cathode lamps were operated at $10 \mathrm{~mA}$ (except for $\mathrm{Cd}, 5 \mathrm{~mA}$ ).

A Nippon Jarrell-Ash AA-1 Mark II atomic absorption spectrometer with an SA-61 slit burner was employed for the determination of tin under the following conditions: wavelength $224.6 \mathrm{~nm}$, air $7.0 \mathrm{dm}^{3} \mathrm{~min}^{-1}$, acetylene $2.5 \mathrm{dm}^{3} \mathrm{~min}^{-1}$, lamp current $10 \mathrm{~mA}$. A Tokyo Rikakikai AU-60C ultrasonic cleaning bath $(28 \mathrm{kHz}, 210 \mathrm{~W})$ was used for the dissolution of tin(IV) hydroxide in nitric acid. All separation procedures, except for centrifugation, were carried out in a Hitachi ECV-843BY clean bench.

\section{Reagents}

Standard solutions $\left(1 \mu \mathrm{g} \mathrm{cm}^{-3}\right.$, in $0.5 \mathrm{~mol} \mathrm{dm}^{-3}$ nitric acid) were prepared from commercial metal standard solutions of $\mathrm{Cu}(\mathrm{II}), \mathrm{Cd}(\mathrm{II}), \mathrm{Pb}$ (II) and $\mathrm{Fe}(\mathrm{III})$. The solutions were further diluted to appropriate concentrations with $0.3 \mathrm{~mol} \mathrm{dm}^{-3}$ nitric acid immediately before use.

All reagents used were of reagent grade, unless otherwise stated. Water was purified by distillation and ion exchange, and then passed through a Millipore Milli$Q$ purification system.

\section{Procedure}

A $2.00-\mathrm{g}$ sample of tin was dissolved in $8-10 \mathrm{~cm}^{3}$ of aqua regia and the solution was diluted to $100 \mathrm{ml}$ with water. A $5-\mathrm{cm}^{3}$ aliquot (containing $100 \mathrm{mg}$ of $\mathrm{Sn}$ ) was placed in a $50-\mathrm{cm}^{3}$ beaker and further diluted to $30 \mathrm{~cm}^{3}$ with water. The $\mathrm{pH}$ was adjusted to $5-6$ with 0.5 and $2 \mathrm{~mol} \mathrm{dm}^{-3}$ sodium hydroxide solutions to form tin(IV) 
hydroxide. The precipitate was separated by centrifugation (at $1000 \mathrm{~g}$ for $10 \mathrm{~min}$ ) and then dissolved in $0.8 \mathrm{~cm}^{3}$ of $14 \mathrm{~mol} \mathrm{dm}^{-3}$ nitric acid, with the aid of ultrasonic irradiation for 5-10 min. The solution was diluted to $\mathrm{ca} .9 \mathrm{~cm}^{3}$ and heated at $50^{\circ} \mathrm{C}$ for $30 \mathrm{~min}$ to precipitate stannic acid. After centrifugation at $1000 \mathrm{~g}$ for $15 \mathrm{~min}$, the supernatant solution was transferred to a $10-\mathrm{cm}^{3}$ volumetric flask and diluted to the mark with water. A $10-\mathrm{mm}^{3}$ aliquot of the solution was injected into a graphite-cuvette for the determination of the trace metals by AAS. The measurement was repeated three times and the absorption readings were averaged. Calibration graphs were prepared by using $1 \mathrm{~mol} \mathrm{\textrm {dm } ^ { - 3 }}$ nitric acid containing trace metals.

\section{Results and Discussion}

\section{Precipitation of tin(IV) hydroxide}

Because tin metal is usually dissolved in aqua regia, the resulting solution is highly acidic and corrosive. Therefore, the desired trace metals should be separated from the solution before the determination. Tin(IV) ions form a bulky and amorphous precipitate by hydrolysis. The precipitate would be called "hydrated tin(IV) oxide" more correctly, but "tin(IV) hydroxide" is generally accepted in the field of separation sciences. The hydroxide is also known as a collector precipitate for many trace elements in aqueous sample solutions. ${ }^{2,7,8}$

Tin(IV) hydroxide was precipitated at pH 5-6 from $30 \mathrm{~cm}^{3}$ of water containing $100 \mathrm{mg}$ of tin(IV) and trace metals. After centrifugation, the supernatant solution was analyzed by ETAAS to obtain the coprecipitation recovery. Table 1 shows that copper(II), cadmium(II), lead(II) and iron(III) are quantitatively coprecipitated with tin(IV) hydroxide.

\section{Precipitation of stannic acid}

A second separation procedure is required for the isolation of the trace metals from the tin matrix. Freshly prepared tin(IV) hydroxide is soluble in nitric acid, but aging of the solution causes the formation of a white precipitate, so-called stannic acid (probably the same as hydrated tin(IV) oxide).

At pH 5-6, tin(IV) hydroxide (100 mg as Sn) was precipitated, centrifuged and then dissolved in varying amounts of $14 \mathrm{~mol} \mathrm{dm}^{-3}$ nitric acid. After the solution was diluted to $10 \mathrm{~cm}^{3}$ with water, this was heated at $50^{\circ} \mathrm{C}$ for $30 \mathrm{~min}$ or allowed to stand for $15 \mathrm{~h}$ at room temperature. The resulting stannic acid was centrifuged; the supernatant solution was analyzed for tin by flame-AAS.

Figure 1 shows that more than $99 \%$ of the tin is removed as stannic acid with $0.25-1.0 \mathrm{~cm}^{3}$ of nitric acid. However, the use of excess nitric acid delayed the precipitation significantly, which rendered the method useless. Therefore, we decided to use $0.8 \mathrm{~cm}^{3}$ of nitric acid and a 30-min heating period.
Table 1 Coprecipitation of trace metals with tin(IV) hydroxide (100 $\mathrm{mg}$ as $\mathrm{Sn})$ at $\mathrm{pH} 5-6$

\begin{tabular}{ccc}
\hline Trace metal & Added $/ \mu \mathrm{g}$ & Coprecipitated, \% \\
\hline $\mathrm{Cu}(\mathrm{II})$ & 1.50 & $97 \pm 2$ \\
& 3.00 & $99 \pm 1$ \\
& 6.00 & $100 \pm 1$ \\
$\mathrm{Cd}(\mathrm{II})$ & 0.15 & $94 \pm 1$ \\
& 0.30 & $97 \pm 1$ \\
& 0.60 & $97 \pm 1$ \\
$\mathrm{~Pb}(\mathrm{II})$ & 1.50 & $96 \pm 1$ \\
& 3.00 & $98 \pm 1$ \\
& 6.00 & $99 \pm 1$ \\
$\mathrm{Fe}(\mathrm{III})$ & 1.50 & $93 \pm 3$ \\
& 3.00 & $96 \pm 1$ \\
& 6.00 & $97 \pm 2$ \\
\hline
\end{tabular}

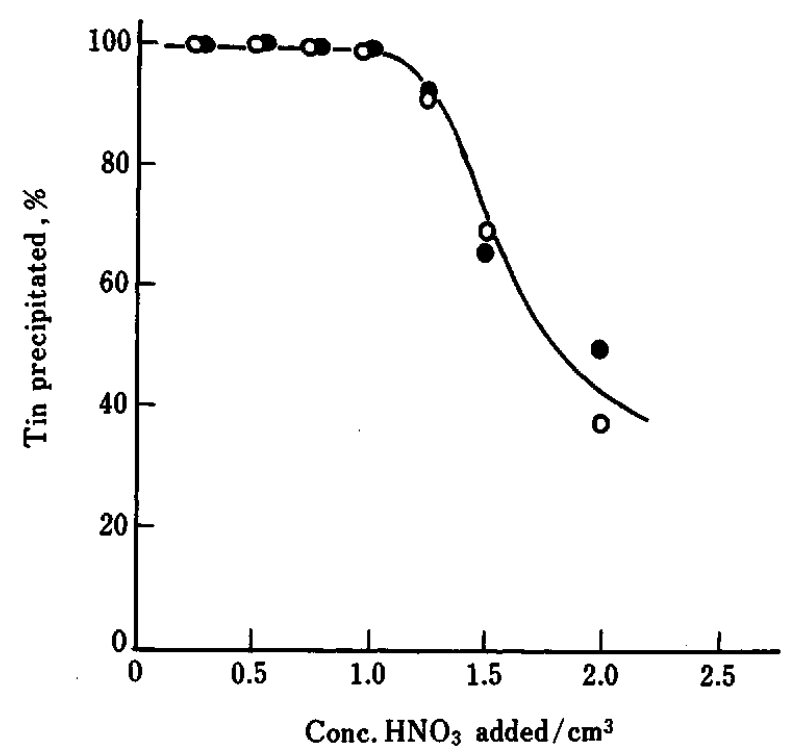

Fig. 1 Effect of acidity on the formation of stannic acid. A nitric acid solution $\left(10 \mathrm{~cm}^{3}\right.$; containing $100 \mathrm{mg}$ of $\left.\mathrm{Sn}\right)$ was heated at $50^{\circ} \mathrm{C}$ for $30 \mathrm{~min}(O)$ or allowed to stand for $15 \mathrm{~h}$ (O).

Recovery of trace metals through the whole procedure

High-purity tin metal $(99.999 \%$, granular, $4-5 \mathrm{~mm}$ in diam., Nacalai Tesque) was dissolved in aqua regia and mixed with different amounts of trace metals, in order to prepare a series of synthetic sample solutions $\left(30 \mathrm{~cm}^{3}\right.$, $100 \mathrm{mg}$ as $\mathrm{Sn}$ ). The matrix precipitation and determination by ETAAS were carried out as described in Procedure.

The equations of the relations between trace metals added ( $\left.Q_{\text {metal }}, \mathrm{ng}\right)$ and found ( $\left.Q_{\text {metal, }}^{\prime}, \mathrm{ng}\right)$ were $Q_{\mathrm{Cu}}^{\prime}=$ $Q_{\mathrm{cu}}+22, Q_{\mathrm{Cd}}^{\prime}=Q_{\mathrm{Cd}}+2.1$ and $Q_{\mathrm{Pb}}^{\prime}=Q_{\mathrm{Pb}}+325$. These results show that copper(II), cadmium(II) and lead(II) are nearly completely recovered through the whole procedure. They also indicate that the impurity contents $\left(\mu \mathrm{g} \mathrm{g}^{-1}\right)$ of the tin metal are 0.22 (for $\mathrm{Cu}$ ), 0.021 (for $\mathrm{Cd}$ ) 
and 3.25 (for $\mathrm{Pb}$ ). The recovery of iron(III), however, was low and values were scattered $(60-80 \%)$, probably because of the occlusion in voluminous stannic acid even in acidic solutions.

The tin accompanying the trace metals was determined by flame-AAS and found to be $0.52-0.59 \mathrm{mg}$ in a $10-\mathrm{cm}^{3}$ final solution. These amounts of tin did not interfere in the subsequent determination of trace metals by ETAAS.

\section{Analysis of high-purity tin metal}

The proposed method was employed as a separation technique for the analysis of commercial high-purity tin metal. Sufficient amounts of sample (e.g., $2.00 \mathrm{~g})$ were dissolved in aqua regia and a 1/20 aliquot was taken for the analysis. Table 2 summarizes the results obtained for two samples: No. 1 (99.999\%, granular, $2-3 \mathrm{~mm}$ in diam., High Purity Chemicals) and No. 2 (99.999\%, granular, 1-3 mm in diam., Katayama Chemicals). Trace metals at the $\mathrm{ng} \mathrm{g}^{-1}$ level were determined with a good precision. The blank values through the whole procedure were lower than the detection limits: $\mathrm{Cu}<20$, $\mathrm{Cd}<1$ and $\mathrm{Pb}<20 \mathrm{ng} \mathrm{g}^{-1}$.

The time required for a determination (including hydroxide precipitation, stannic acid formation and ETAAS for 3 elements) was about $90 \mathrm{~min}$. This simple matrix precipitation can be applicable to the multielement separation of impurities (e.g., $\mathrm{Co}, \mathrm{Ni}, \mathrm{Cu}, \mathrm{Zn}, \mathrm{Cd}$ and $\mathrm{Pb}$ ) from the tin matrix, because these trace metals are expected to behave similarly.
Table 2 Analysis of high-purity tin metal

\begin{tabular}{cccc}
\hline \multirow{2}{*}{ Sample $^{\mathrm{a}}$} & \multicolumn{3}{c}{ Trace metal $^{\mathrm{b}} / \mu \mathrm{g} \mathrm{g}^{-1}$} \\
\cline { 2 - 4 } & $\mathrm{Cu}$ & $\mathrm{Cd}$ & $\mathrm{Pb}$ \\
\hline No. 1 & $0.15(8.8)$ & $0.004(9.6)$ & $2.59(9.5)$ \\
No. 2 & $0.38(8.2)$ & $0.009(7.1)$ & $4.69(2.9)$ \\
\hline
\end{tabular}

a. $100 \mathrm{mg}$ of tin was taken.

b. $\operatorname{RSD}(\%, n=5)$ in parentheses.

\section{References}

1. J. Minczewski, J. Chwastowska and R. Dybczynski, "Separation and Preconcentration Methods in Inorganic Trace Analysis", Ellis Horwood, Chichester, 1982.

2. A. Mizuike, "Enrichment Techniques for Inorganic Trace Analysis", Springer, Berlin, 1983.

3. Yu. A. Zolotov and N. M. Kuz'min, "Preconcentration of Trace Elements", Elsevier, Amsterdam, 1990.

4. Japanese Industrial Standards Committee, “Methods for Chemical Analysis of Tin Metal" (JIS H 1141), Tokyo, 1993.

5. K. Takada, Bunseki Kagaku, 32, 197 (1983).

6. T. M. Rettberg and J. A. Holcombe, Anal. Chem., 60, 600 (1988).

7. M. Hiraide, Z. S. Chen, K. Sugimoto and H. Kawaguchi, Anal. Chim. Acta, 302, 103 (1995).

8. M. Hiraide, K. Ishikawa, Z. S. Chen and H. Kawaguchi, Mikrochim. Acta, 117, 7 (1994).

(Received June 29, 1995)

(Accepted October 16, 1995) 